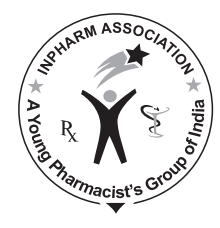

\title{
Taste Masking and Molecular Properties of Metformin Hydrochloride-Indion 234 Complexes
}

\author{
Bhoyar PK, Amgaonkar YM \\ Department of Pharmaceutics, S.K.B. College of Pharmacy, New Kamptee, Dist: Nagpur, \\ Maharashtra, India \\ Address for correspondence: Mr. Pravin Bhoyar; E-mail: pravinbhoyar007@rediffmail.com
}

\begin{abstract}
Metformin hydrochloride is an oral antidiabetic biguinide agent, used in the management of non-insulin-dependent (type-2) diabetes mellitus. The purpose of present work was to formulate tasteless complexes of metformin hydrochloride with indion 234 and to evaluate molecular properties of drug complexes. The drug loading onto ion-exchange resin was optimized for mixing time, activation, effect of $\mathrm{pH}$, mode of mixing, ratio of drug to resin, and temperature. Drug resin complexes (DRC) were evaluated for taste masking and characterized by $\mathrm{x}$-ray diffraction study and infrared spectroscopy. Metformin hydrochloride release from DRC is obtained at salivary and gastric $\mathrm{pH}$ and in the presence of electrolytes. The efficient drug loading was evident in batch process using activated indion 234 with a pH of 3.5 and drug-resin ratio of 1:1.2, while temperature enhances the complexation process. Infrared spectroscopy revealed complexation of $-\mathrm{NH}$ (drug) with indion 234. DRC are amorphous in nature. Drug release from DRC in salivary $\mathrm{pH}$ was insufficient to impart bitter taste. Volunteers rated the complex as tasteless and agreeable. Complete drug release was observed at gastric $\mathrm{pH}$ in $3 \mathrm{~h}$. The drug release was accelerated in the presence of electrolytes. Indion 234 is inexpensive, and the simple technique is effective for bitterness masking of metformin.
\end{abstract}

Key words: Characterization, electrolyte release, metformin hydrochloride, Indion 234, tasteless complex

\section{INTRODUCTION}

Undesirable taste is one of several important formulation problems that are encountered with certain drugs. The problem of bitter and obnoxious taste of it is a challenge

\begin{tabular}{|l|l|}
\hline \multicolumn{2}{|c|}{ Access this article online } \\
\hline Quick Response Code: & \\
\hline & Website: \\
& www.jyoungpharm.in \\
& \\
\hline DOI: & $10.4103 / 0975-1483.80294$ \\
\hline
\end{tabular}

to the pharmacist in the present scenario. ${ }^{[1]}$ Taste of a pharmaceutical product is an important parameter for governing compliance. Thus, taste masking of oral pharmaceuticals has become an important tool to improve patient compliance and the quality of treatment especially in pediatrics and geriatric. Therefore, formulation of tastemasked products is a challenge to the pharmacists. ${ }^{[2,3]}$

Metformin hydrochloride is an orally administered antihyperglycemic agent, used in the management of type 2 diabetes (NIDDM) and type 1 diabetes (IDDM). It is a very bitter drug and highly soluble in water. ${ }^{[4]}$ The purpose of this research was to formulate tasteless complexes of metformin with indion 234 and evaluate the molecular 
properties of drug complexes. Indion 234 is an inexpensive resin, and a simple, rapid, and cost-effective method was attempted. Drug complexation with ion exchange resins is mentioned in certain patents; however, the molecular properties of drug resinate and the effect of electrolytes on drug release from complex have not been investigated much. ${ }^{[5-7]}$ The natural variations in $\mathrm{pH}$ can be used advantageously to prepare complexes that remain stable in the mouth without affecting gastric release. Metformin has requisite aqueous solubility, $\mathrm{pKa}$ (11.5), and exchangeable secondary amine moiety. Indion 234, a water-insoluble, high molecular weight, polycarboxylic acid resin is a highly porous indigenous resin. A batch process of complexation is optimized with reference to drug loading, temperature, and $\mathrm{pH}$. The molecular properties of optimized complex and the effect of electrolyte on drug release are reported.

\section{MATERIALS AND METHODS}

\section{Material}

Metformin hydrochloride-IP was a Gift sample from Zim Laboratories (Nagpur, India). Indion 254 and Indion 264 were obtained from Ion Exchange India Ltd (Mumbai, India). Sodium chloride, calcium chloride, and other chemicals of ultrapure grade were purchased locally.

\section{Methods}

\section{Preliminary evaluation of resin}

Accurately weighed (1 g) resin samples were kept in oven (previously heated to $100{ }^{\circ} \mathrm{C}$ ) for $24 \mathrm{~h}$ and weighed. The difference in the weight before and after drying gave moisture content. Indion 234 particle diameter was measured microscopically. Water absorption time was obtained by keeping $500 \mathrm{mg}$ of indion 234 in contact with $1 \mathrm{~mL}$ of water in a Petri dish. The time required for complete water absorption was recorded.

\section{Preparation of resinate}

Resinates were prepared using the batch process. ${ }^{[8,9]}$ The resin was rewashed with water until neutral $\mathrm{pH}$ was reached. DRC was prepared by placing $100 \mathrm{mg}$ of activated resin in a beaker containing $50 \mathrm{~mL}$ of deionized water. Accurately weighed metformin hydrochloride was added and stirred for $180 \mathrm{~min}$. The mixture was filtered through Whatman filter paper no.41 and residue was washed with $50 \mathrm{~mL}$ of deionized water. Unbound drug in filtrate was estimated at $233.5 \mathrm{~nm}$ and drug loading efficiency was calculated. ${ }^{[10]}$

Optimization of metformin bydrochloride-Indion 234 complexation The drug loading on to resin was optimized for various parameters such as mixing time, activation, effect of $\mathrm{pH}$, mode of mixing, ratio of drug: resin and effect of temperature. These parameters were studied and optimized for the maximum amount of drug loading.

Effect of stirring time on drug loading

For optimization of stirring time on drug loading, accurately weighed metformin hydrochloride $(100 \mathrm{mg})$ was added to $100 \mathrm{mg}$ of resin and slurred in $50 \mathrm{~mL}$ of deionized water. Six batches with a stirring time of 30, 60, 90, 120, 180, and $240 \mathrm{~min}$ were processed. Amount of bound drug at the end was estimated at $233.5 \mathrm{~nm}$ by UV spectroscopy and the time required for maximum loading of drug was optimized.

\section{Effect of resin activation}

Indion 234 placed on a Whatman filter paper in a funnel was washed with deionized water and subsequently with $1 \mathrm{~N} \mathrm{HCl}$. The resin was rewashed with water until neutral $\mathrm{pH}$ was reached. Drug: resin complexes were prepared by placing $100 \mathrm{mg}$ of acid-activated resin in a beaker containing $50 \mathrm{~mL}$ deionized water. Metformin hydrochloride $(100 \mathrm{mg})$ was added to resin slurry with magnetic stirring for $3 \mathrm{~h}$. On filtration, the residue was washed with $50 \mathrm{~mL}$ of deionized water. Unbound drug in filtrate was estimated at $233.5 \mathrm{~nm}$. Similarly, alkali activation of Indion 234 was performed, replacing $1 \mathrm{~N} \mathrm{HCl}$ with $1 \mathrm{~N} \mathrm{NaOH}$. Finally, Indion 234 was also activated with combined treatment of $1 \mathrm{~N} \mathrm{HCl}$ and $1 \mathrm{~N} \mathrm{NaOH}$ solutions. The drug loading efficiency of activated resin was evaluated spectrophotometrically.

\section{Effect of $p H$ on complex formation}

For optimization of $\mathrm{pH}$, weighed, $100 \mathrm{mg}$ of drug was added to $100 \mathrm{mg}$ of activated resins in $50 \mathrm{~mL}$ of distilled water. The $\mathrm{pH}$ of solutions were adjusted at 2, 3, 3.5, 4.0, 5, and 6.0 stirred for $3 \mathrm{~h}$ and the drug content was determined.

\section{Effect of mode of mixing on drug loading}

For optimization of mode of mixing, Rotary shaker and Magnetic stirrer were used. All activated resins $(100 \mathrm{mg})$ in $50 \mathrm{~mL}$ of distilled water and about $100 \mathrm{mg}$ of drug. The $\mathrm{pH}$ was adjusted at 3.5 and drug content was determined.

\section{Optimization of drug:resin ratio}

For optimization of ratio of drug: resin, three batches were prepared containing drug-resin in the ratio of 1:1, 1:2, 1:3. Accurately weighed metformin hydrochloride (as per $1: 1,1: 2$, and $1: 3$, drug:resin ratio) was added in $50 \mathrm{~mL}$ of deionized water. The $\mathrm{pH}$ was maintained at 3.5 and stirred for $3 \mathrm{~h}$. The mixture was filtered and residue was washed with $50 \mathrm{~mL}$ of deionized water. Unbound drug in filtrate was estimated at $233.5 \mathrm{~nm}$ and drug loading efficiency was calculated. 


\section{Effect temperature on complex formation}

For optimization of temperature on drug loading, accurately weighed metformin hydrochloride (100 mg) was added to $120 \mathrm{mg}$ of activated resin and slurred in 50 $\mathrm{mL}$ of deionized water at $30^{\circ} \mathrm{C}, 35^{\circ} \mathrm{C}, 40^{\circ} \mathrm{C}, 50^{\circ} \mathrm{C}$, and $60^{\circ} \mathrm{C}$ using temperature-controlled magnetic stirring for $180 \mathrm{~min}$. The $\mathrm{pH}$ was maintained at 3.5 and the effect of temperature on drug loading was studied.

\section{Molecular properties of drug resin complex}

Infrared spectra of metformin hydrochloride, indion 234, and DRC (optimized ratio) were recorded over the wave no. 4000 to $400 \mathrm{~cm}^{-1}$ to check the interaction in the resinate on Jasco Dispersive type FT-IR spectrophotometer using the $\mathrm{KBr}$ disk technique. Then the spectra were comparatively analyzed for drug interaction.

The powder x-ray diffraction patterns (XRDP) of metformin hydrochloride, indion 234, and DRC (optimized ratio) were subjected to $\mathrm{x}$-ray diffraction study for the confirmation of complex formation. X-ray diffraction studies were carried out on Phillips analytical X-ray BV (pw1710) using $\mathrm{Cu}$ anode $40 \mathrm{KV}$ voltage and $30 \mathrm{~mA}$ current.

Taste evaluation of solid drug: resin complex

Drug resin complex $(1: 1.2)$ was subjected to sensory evaluation by a panel of nine members using the time intensity method. The pure drug without complexation with ion exchange resin was used as control in this study. Sample equivalent to $200 \mathrm{mg}$ (dose of drug) was held in mouth for $10 \mathrm{~s}$. Bitterness was recorded instantly and then after 20, 30, 40, 50, and $60 \mathrm{~min} .{ }^{[11]}$ The evaluation was performed by classifying bitter taste into five classes. Level 0: No bitter taste is sensed, 1: Acceptable bitterness, 2: Slightly bitterness, 3: Moderately bitterness Level 4: Strongly bitterness. Descriptive statistics mean and standard deviation were calculated for all variables as shown in Table 1 . The paired $t$-test was applied using INSTAT software. $P$-value $<0.05$ has been considered as statistical significant level.

$\begin{aligned} & \text { Table 1: Volunteers opinion test for metformin } \\
& \text { hydrochloride before and after taste masking }(\mathbf{n = 9 )}\end{aligned}$
\begin{tabular}{lcc} 
Time & $\begin{array}{c}\text { Before taste masking } \\
\text { (seconds) }\end{array}$ & $\begin{array}{c}\text { After taste masking } \\
\text { Mean } \pm \text { SD }\end{array}$ \\
\hline 10 & $4.0 \pm 0.00^{* *}$ & $0.2 \pm 0.44^{* *}$ \\
20 & $3.3 \pm 0.50^{* *}$ & $0.1 \pm 0.33^{* *}$ \\
30 & $2.5 \pm 0.52^{* *}$ & 0 \\
40 & $2.0 \pm 0.50^{* *}$ & 0 \\
50 & $1.7 \pm 0.44^{* *}$ & 0 \\
60 & $1.2 \pm 0.44^{* *}$ & 0 \\
\hline$P<0.001^{* *}$ &
\end{tabular}

Drug release from $\mathrm{DRC}$

Drug release from DRC (1:1.2) in deionized water was determined using USP type II apparatus (paddle type) at 100 rpm with temperature of $37^{\circ} \mathrm{C} \pm 0.5^{\circ} \mathrm{C}$. DRC equivalent to $200 \mathrm{mg}$ of drug was weighed accurately and added to $900 \mathrm{~mL}$ deionized water. Drug release was performed for $30 \mathrm{~min}$. A $5 \mathrm{~mL}$ sample removed from mixtures each kept at 5 to $30 \mathrm{~min}$ was filtered and further diluted with $100 \mathrm{~mL}$ of deionized water and the amount of drug was estimated spectrophotometrically. Similarly, drug release from DRC was performed at $\mathrm{pH} 1.2$, replacing deionized water with $900 \mathrm{~mL}$ of $0.1 \mathrm{~N} \mathrm{HCl}$ for $180 \mathrm{~min}$. Drug release from the DRC was also performed in $10 \mathrm{~mL}$ of $\mathrm{pH} 6.7$ solution by adding $200 \mathrm{mg}$ of the DRC to a test tube. The mixture was filtered after shaking for $60 \mathrm{~s}$. Further dilutions were made and the filtrates were analyzed for drug.

Drug release from DRC was performed in $\mathrm{NaCl}$ solutions (0.0015 M, 0.015 M, and 0.15 M) using USP 24 type II dissolution apparatus $\left(37^{\circ} \mathrm{C}, 900 \mathrm{~mL}, 100 \mathrm{rpm}\right)$ for $30 \mathrm{~min}$. Similar study was performed in $\mathrm{CaCl}_{2}$ solutions $(0.0015 \mathrm{M}$, $0.015 \mathrm{M}$, and $0.15 \mathrm{M}$ ). The effect of electrolytes on drug release from DRC is determined.

\section{RESULTS AND DISCUSSION}

\section{Optimization of metformin hydrochloride-Indion 234 complexation}

Metformin hydrochloride is an oral antidiabetic biguinide agent, used in the management of non-insulin-dependent (type-2) diabetes mellitus, is extremely bitter resulting in poor patient compliance. Complexation with ion exchange resin is a simple and efficient technique of masking the bitterness. The drug being soluble in water has desired ionization power. The $\%$ moisture content in the Indion 234 resin was found to be $6.2 \%$. The size of Indion 234 particles obtained was $49 \pm 4 \mu \mathrm{m}$, which is useful for taste masking. Substantially small size particles are difficult to process and particles greater than $150 \mu \mathrm{m}$ have a tendency to fracture. The water uptake time of Indion 234 was found to be $60 \mathrm{~s}$.

Metformin hydrochloride was loaded on Indion 234 by the batch process. Complexation is essentially a process of diffusion of ions between the resin and surrounding drug solution. ${ }^{[12]}$ As reaction is equilibrium phenomenon, maximum efficacy is best achieved in the batch process.

The equilibrium ion exchange in solution occurs stoichiometrically and hence is affected by stirring time. The percentage drug loading (wt/wt) with a stirring time 
of $30,60,90,120,180$, and $240 \mathrm{~min}$ was found to be $42.32 \%$ $\pm 0.73 \%, 51.56 \% \pm 0.82 \%, 63.73 \% \pm 1.45 \%, 68.76 \% \pm$ $0.67 \%, 74.56 \% \pm 0.92 \%$, and $75.73 \% \pm 0.45 \%$, respectively. This finding may indicate the significant involvement of Van Der Waals forces or chemisorption taking place along with drug exchange during complexation. ${ }^{[13]}$ Hence, 180 min contact time between drug and resin could be optimized to equilibrate the ion exchange process to achieve maximum drug loading.

Highest drug binding on resin was achieved when activated with both acid-alkali treatments. The percentage drug loading with inactivated resin, treated with acid, alkali, and combination thereof was found to be $74.56 \% \pm 0.92 \%$, $82.78 \% \pm 1.19 \%, 80.93 \% \pm 0.34 \%$, and $83.62 \% \pm 0.94 \%$ wt/wt, respectively. Highest drug binding on resin was achieved when activated with both acid-alkali treatments. Impurity associated with industrial scale manufacture or absorbed during storage or handling may be neutralized by treating with combined solution. The combined resin activation exposed the exchangeable groups producing rapid drug exchange and hence higher drug binding.

Metformin-Indion 234 complexation involves the exchange of ionizable drug and metal ions in resin. Such a mode of complexation between amino group of metformin and -COO-K+ functionality of Indion 234 can be affected by the $\mathrm{pH}$ of the reacting media. The complexation was enhanced with increasing $\mathrm{pH}$ from 2 to 4 as shown in Figure 1. A maximum of $87.90 \% \pm 0.62 \%$ wt/wt drug loading was obtained at $\mathrm{pH} 3.5$. As $\mathrm{pH}$ increased above 4 , the percentage drug loading decreased. The $\mathrm{pH}$ of the solution affects both solubility and the degree of ionization of drug and resin. The results can be attributed to the fact that cationic drug is ionized at lower $\mathrm{pH}$ value and hence demonstrate high binding capacity, while at higher $\mathrm{pH}$ protonated fraction of cationic drug decreases and interaction with resin also decreases. ${ }^{[14-16]}$ Hence, metformin

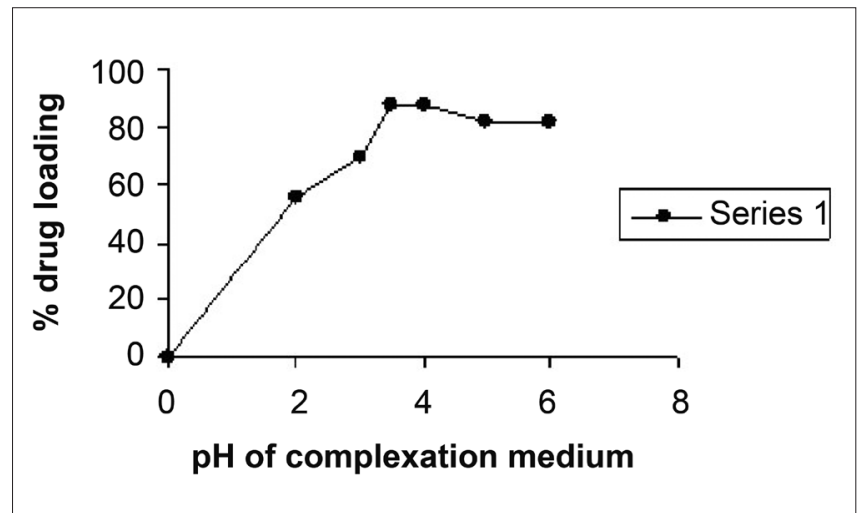

Figure 1: Effect of reaction medium $\mathrm{pH}$ on percent drug loading. hydrochloride as a cationic drug will have maximum solubility and complete ionization in this range. Decrease complexation at lower $\mathrm{pH}$ i.e. below 2 is due to excess $\mathrm{H}^{+}$ ions in solution which have more binding affinity to the $-\mathrm{COO}^{-}$group of resin and compete with drug for binding.

Complexation was found to be optimum in case of stirring, a maximum of $87.26 \% \pm 0.62 \% \mathrm{wt} / \mathrm{wt}$ and in case of shaking $75.83 \% \pm 1.23 \% \mathrm{wt} / \mathrm{wt}$. This finding may indicate the significant involvement of Van Der Waals forces taking place along with drug exchange during complexation.

The drug-loading efficiency for a drug-resin ratio 1:1, 1:2, and $1: 3$ of the batch process was $87.26 \% \pm 0.62 \%, 94.56 \%$ $\pm 0.68 \%$, and $94.85 \% \pm 1.51 \% \mathrm{wt} / \mathrm{wt}$. It is due to the fact that, increase in the amount of resin increases the amount of drug adsorbed from the solution. A $7 \% \mathrm{wt} / \mathrm{wt}$ increase of loading efficiency was observed in batch process, when the drug-resin ratio was changed from 1:1 to 1:2. Hence, the drug loading performed at an intermediate drug-resin ratio of $1: 1.2,1: 1.4,1: 1.6$, and 1:1.8 was found to be $94.30 \% \pm 1.56 \%, 94.52 \% \pm 0.23 \%, 94.20 \% \pm 0.87 \%$, and $94.26 \% \pm 0.37 \% \mathrm{wt} / \mathrm{wt}$, respectively. Although drug binding was comparable, metformin dose ranging from 300 to $500 \mathrm{mg}$ and the higher resin ratio in the latter (1:1.4) would be difficult to accommodate in tablet formulations. The drug-resin ratio of 1:1.2 has optimum drug loading. Santos and Ghaly ${ }^{[17]}$ have reported a loading efficiency of $38.6 \%$ for cimetidine using amberlite 69 . In the case of metformin hydrochloride and Indion 234, a drug-loading efficiency of more than $87 \% \mathrm{wt} / \mathrm{wt}$ was achieved even with a drug-resin ratio of 1:1.

The $\%$ drug loading $(\mathrm{w} / \mathrm{w})$ with temperature of $30^{\circ} \mathrm{C}$, $35^{\circ} \mathrm{C}, 40^{\circ} \mathrm{C}, 50^{\circ} \mathrm{C}$, and $60^{\circ} \mathrm{C}$ was found to be $91.24 \pm 1.86$, $92.67 \% \pm 0.45 \%, 95.36 \pm 1.24,97.34 \pm 1.25$, and $97.42 \pm$ 0.86 , respectively. These figures reveal that as temperature increases percentage of drug loading also increases rapidly upto $50^{\circ} \mathrm{C}$. Increase in temperature above $50^{\circ} \mathrm{C}$ did not further increase the percentage drug loading. Increased temperature during complexation increases ionization of drug and resin. Higher temperatures tend to increase the diffusion rate of ions by decreasing the thickness of exhaustive exchange zone. ${ }^{[18]}$ Also at increased temperature, swelling of resin takes place. Due to swelling ionic sites are open for exchange of counter ions. ${ }^{[19]}$

\section{Molecular properties of drug-resin complexes}

The infrared spectra of drug, Indion 234 resin, and resinate are depicted in Figure 2. FT-IR spectra of drug show a prominent peak at $1028 \mathrm{~cm}^{-1}$ corresponding to 


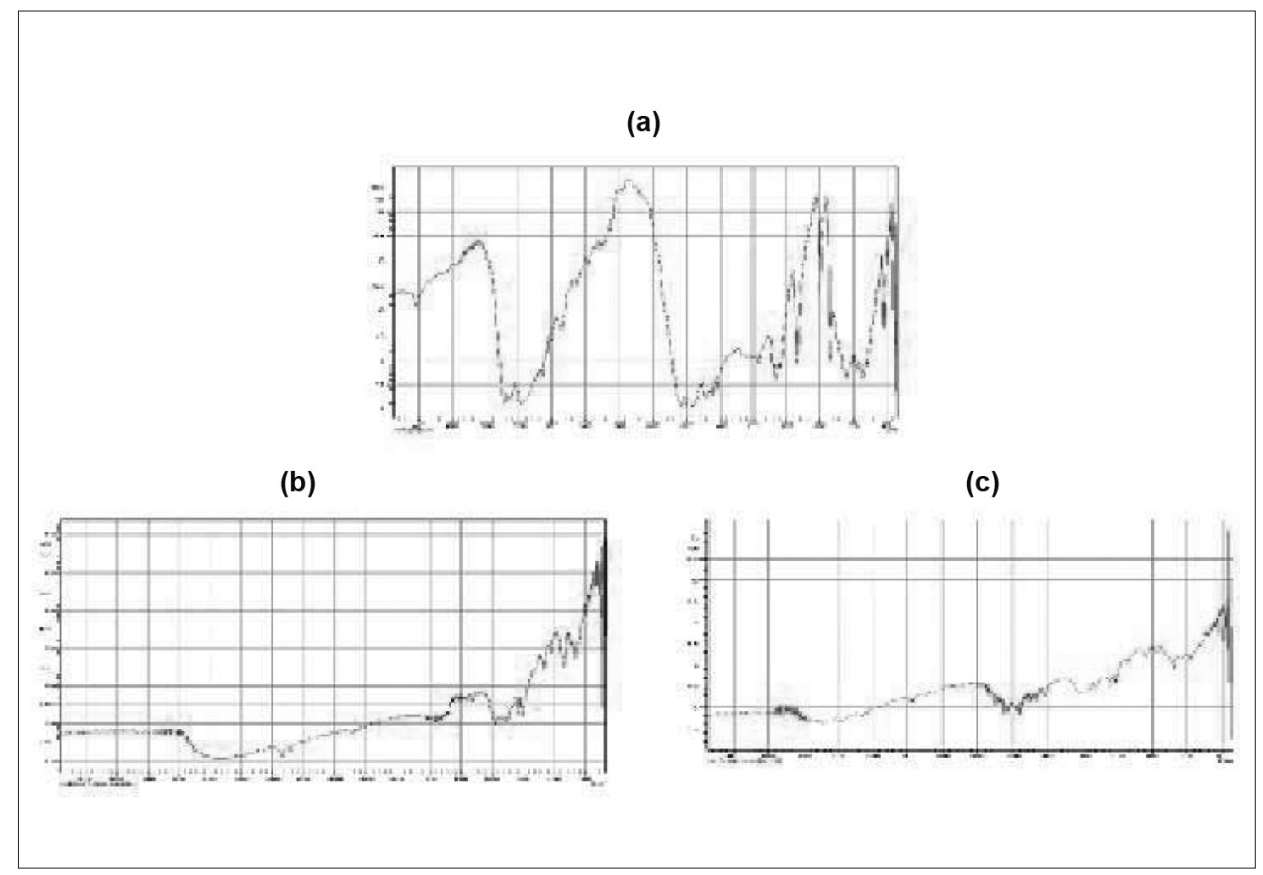

Figure 2: FT-IR spectra of (a) metformin hydrochloride, (b) Indion 234 resin, (c) Indion 234 resinate.

the NH stretching in a secondary amine. Indion 234 shows characteristic peaks at $1674 \mathrm{~cm}^{-1}$, at $1764 \mathrm{~cm}^{-1}$ corresponding to $-\mathrm{C}=\mathrm{O}$ stretching of aryl acids, and at $1602 \mathrm{~cm}^{-1}$ due to aromatic $\mathrm{C}=\mathrm{C}$ stretching. Numbers of overtone peaks were observed at 2308 and $2347 \mathrm{~cm}^{-1}$. The absence of peak at $1028 \mathrm{~cm}^{-1}$ in DRC (1:1.2) confirms the complexation of the secondary amine group in the drug with resin.

The x-ray diffraction study of metformin hydrochloride shows highly crystalline nature. Resin Indion 234 showed amorphous nature. The molecular state of the drug prepared as DRC shows a hollow diffused pattern and the absence of drug peaks having noncrystalline characteristics. This finding confirms that the entrapped drug is dispersed monomolecularly in the resin bead and this might be because of entrapment of drug molecule in the polymer matrix of the resins. From all the evidences it can be concluded that the drug resinate was a chemical complex [Figure 3]. Studies have shown that the molecules of the entrapped drug changes from crystalline to amorphous state.

\section{Drug release from the drug-indion complex}

Metformin release from the drug-resin adsorbate was observed in deionized water for $30 \mathrm{~min}$, in average salivary $\mathrm{pH}$ of 6.7, and at gastric $\mathrm{pH}$ of 1.2, separately. Less than $0.8 \% \mathrm{wt} / \mathrm{vol}$ of drug was released in deionized water in
30 min, indicating the stability of complexes. In vitro drug release in average salivary $\mathrm{pH}$ of 6.7 was less than $8 \%$ within $60 \mathrm{~s}$. The presence of exchangeable ions of ionizable electrolytes in the salivary fluid may be responsible for this release. The DRC is stable in salivary $\mathrm{pH}$ for a period of administration. The amount released is insufficient to impart bitter taste, while the formulation passes through the mouth to further parts of the gastrointestinal (GI) tract. At gastric $\mathrm{pH} 1.2,74 \%$ of metformin was released within $120 \mathrm{~min}$, and the release was complete in $180 \mathrm{~min}$. The hypothesis that the drug-release equilibrium, similar to drug loading, is highly dependent on the physiological $\mathrm{pH}$ can be applied for taste masking without affecting the dosage form characteristics.

The exchange process of drug release follows Equation 1.

$\operatorname{Resin}^{-}-\operatorname{Drug}^{+}+\mathrm{X}^{+} \rightarrow \operatorname{Resin}^{-}-\mathrm{X}^{+}+\operatorname{Drug}^{+}$, (1)

Where, $\mathrm{X}^{+}$represents the ions in the GI tract.

Particle diffusion and film diffusion are sequential steps in drug release by the ion exchange process. ${ }^{[20]}$ Indion 234-metformin complex hydrates by water absorption and then swells in diffusion media, and the subsequent exchange process releases the drug. There was no drug release in plain deionized water because metformin hydrochloride was completely ionized and therefore bound to the resin. Drug release at pH 6.7 and cation concentration of 40 


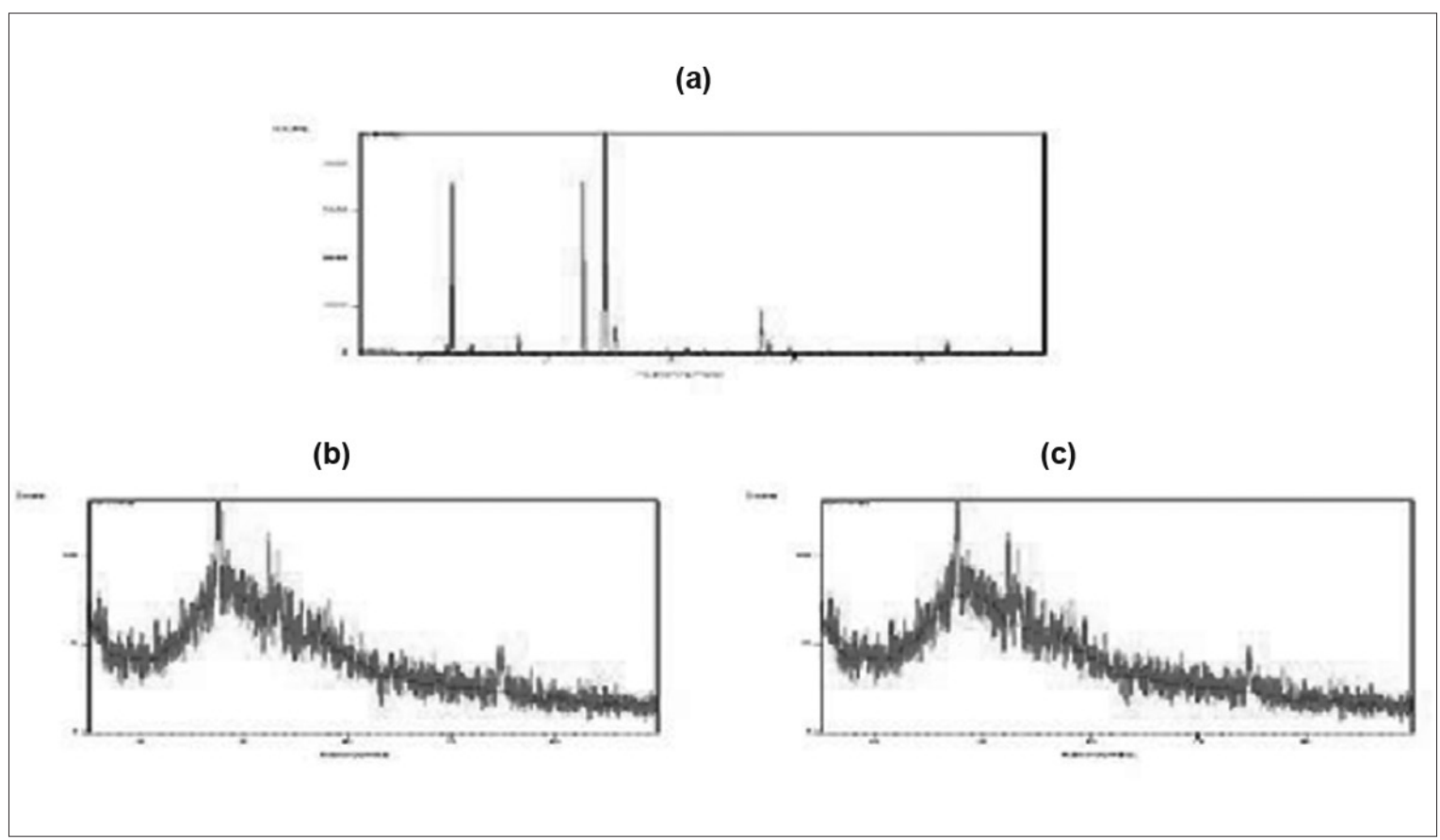

Figure 3: X-ray diffraction pattern of (a) metformin hydrochloride, (b) Indion 234 resin, (c) Indion-234 resinate.

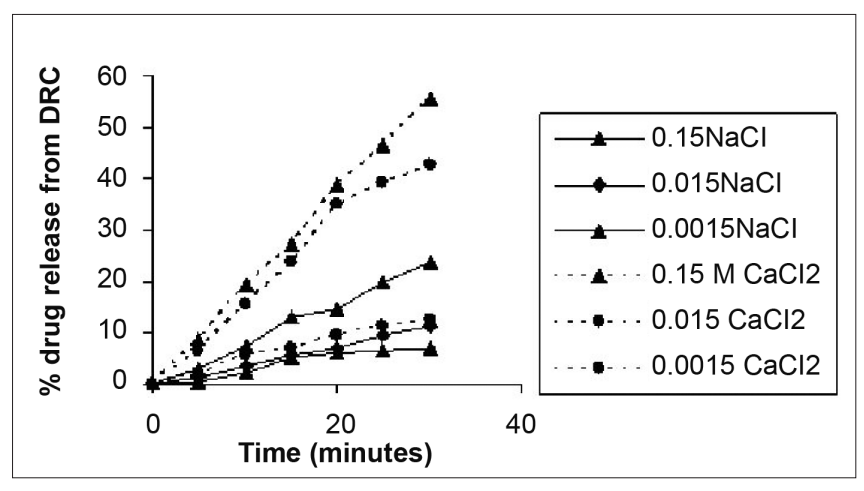

Figure 4: Effect of electrolytes on metformin hydrochloride release from complexes.

$\mathrm{mEq} / \mathrm{L}$ in a short period of ingestion does not alter the exchange process. The complexation of metformin hydrochloride with Indion 234 produces amorphous tasteless drug resinates.

Taste evaluation in volunteers confirmed that the taste of ciprofloxacin was masked by complexing with Indion 234. The majority of the volunteers found the DRC to be tasteless and agreeable. When DRC is exposed to a low $\mathrm{pH}$, it causes dissociation of the complex. The presence of $\mathrm{H}^{+}$ion in the medium causes displacement of metformin, thus facilitating drug release. This finding has been well supported by XRPD data and confirmed by in vitro drug release in salivary $\mathrm{pH}$.
Figure 4 shows the effect of the ionic strength of salts on drug release from DRC. It may be noted that an insignificant amount of drug was released $(0.8 \%)$ in plain deionized water. The drug release from complex increased as the concentration of electrolyte increased in the medium. In a solution of $0.0015 \mathrm{M}$ and $0.015 \mathrm{M} \mathrm{NaCl}$, drug release showed an insignificant difference. However, increased release of $23.6 \%$ was observed in $0.15 \mathrm{M} \mathrm{NaCl}$ solution. Similarly, increasing the $\mathrm{CaCl}_{2}$ concentration in the medium increased the drug release from DRC. The effect of divalent calcium ions was more pronounced than monovalent sodium ions. Drug release of $12 \%, 42 \%$, and $55 \%$ within 30 min was observed with respect to $0.0015 \mathrm{M}, 0.015 \mathrm{M}$, and $0.15 \mathrm{M} \mathrm{CaCl}_{2}$ in solution.

Electrostatic interactions govern the equilibrium distribution of the drug species between the resin and solution phases. ${ }^{[21-23]}$ The influence of salt concentration on the release rate can be explained by solute diffusion. The metformin release from DRC is controlled by an ion exchange mechanism. The exchange rate is dominated by the rate at which the competing ions diffuse from the media to resin. Solute diffusion is driven by a concentration gradient. At high salt concentration, the concentration gradient is greater, resulting in faster diffusion of ions, and thereby a higher release rate. Valency of the counter ions influences exchange capacity. The rate of sorption of the divalent calcium ions was much faster as compared with 
$\mathrm{Na}^{+}$ions, which are less firmly bound. Also, the selectivity of carboxylic acid resins is higher for divalent calcium ions. Even though larger size $\mathrm{Ca}_{2}{ }^{+}$ions are expected to diffuse slowly, their valency enhances the drug release. Drug release is a reverse process to drug loading, both involve ions that compete for ionic binding sites with the drug.

\section{CONCLUSION}

The batch process of complexing metformin hydrochloride with indion 234 produced efficient drug loading. The drug release from the DRC increased with the salt concentration, and the effect was more pronounced with divalent calcium ions. The volunteers rated the complexes as tasteless and agreeable.

\section{ACKNOWLEDGEMENTS}

The authors wish to thank Ion Exchange India Ltd, Mumbai, India, for providing indion 234 resin sample. The authors wish to thank University Department of Physics, Nagpur, India, for providing $\mathrm{x}$-ray diffraction facility.

\section{REFERENCES}

1. Chatap VK. A review on taste masking methods for bitter drug. Pharmainfo Net 2007;5:45-9.

2. Mundada AS, Bhalekar MR, Avari JG. Formulation and evaluation of dispersible taste masked tablet of roxithromycin. Asian J Pharm 2008;2:32-7.

3. Nanda AR, Kandarapu, Garg S. An update on taste masking technologies for oral pharmaceuticals. Indian J Pharm Sci 2002;64:10-7.

4. Hermann LS, Melender A. Biguanides: basic aspects and clinical use. New York: Wiley; 1992. p. 292-7.

5. Akkaramongkolporn P, Yonemochi E, Terada K. Molecular state of chlorpheniramine in resinates. Chem Pharm Bull 2000;48:231-4.

6. Akkaramonkolporn P, Terada K, Yonemochi E. Molecular properties of propranolol hydrochloride prepared as drug-resin complexes. Drug Dev Ind Pharm 2001;27:359-64.

7. Pisal S, Zainnuddin R, Nalawade P, Mahadik K, Kadam S. Molecular
Properties of ciprofloxacin-Indion 234 complexes. AAPS Pharm Sci Tech 2004;5:e62.

8. Avari JG, Bhalekar M. Cation exchange resins for taste masking and rapid dissolution of sparfloxacin. Indian Drugs 2004;4:19-23.

9. Pisal S, Nalawade P, Mahadik K, Kadam S. Molecular properties of ciprofloxacin- indion 234 complexes. AAPS Pharm Sci Tech 2004;62:1-8.

10. Raghunanthan Y, Amsel L, Hinsvark ON, Bryant WJ. Sustained release drug delivery system. I: Coated ion-exchange resin system for phenylpropanolamine and other drugs. J Pharm Sci 1981;70:379-83.

11. Borodkin S, Yunker MH. Interaction of amine drugs with a polycarboxylic acid ion- exchange resin. J Pharm Sci 1970;59:481-6.

12. Borodkin SS. Ion exchange resins and sustained release. In: Swarbrick J, Boylan JC, editors. Encyclopedia of Pharmaceutical Technology. New York: Marcel Dekker; 1993. p. 241-3.

13. Kuchekar BS, Badhan AC, Mahajan HS. Mouth dissolving tablets of salbutamol sulphate: a novel drug delivery system. Indian Drugs 2004;41:592-8.

14. Pisal S, Zainnuddin R, Nalawade P, Mahadik K, Kadam S. Molecular properties of ciprofloxacin- indion 234 complexes. AAPS Pharm Sci Tech 2004;5:1-8.

15. Quality control methods for medicinal plants. World Health Organization; 1998. p. 38-40.

16. Bhalekar M, Avari JG, Jaiswal BS. Cation exchangers in pharmaceutical formulations. Indian J Pharma Educ 2004;38:184-8.

17. Santos L, Ghaly ES. Design and development of suspension containing drug resin complex. AAPS Pharm Sci Tech 2003;5:32-57.

18. Frank D, Koebel B. Some like it hot, some like it cold. Water Quality 2000;54:54-7.

19. Bhoyar PK, Biyani DM. Formulation and evaluation of sustained release dosage form with taste masking of metformin hydrochloride using indion resin. Res J Pharm Dosage Form and Tech 2009;1:47-51.

20. Conaghey OM, Coris J, Corrigan OI. The release of nicotine from a hydrogel containing ion exchange resins. Int J Pharm 1998;170:215-24.

21. Jasari T, Vuorio M. Ion exchange fibers and drugs: an equilibrium study. J Control Release 2001;70:219-29.

22. Herrera T, Matejka Z, Eliasek J. Cation exchange kinetics on carboxylic acid resins in a multicomponent system $\mathrm{H}-\mathrm{Me}+-\mathrm{Me} 2+$. Desalination 1983;48:161-9.

23. Liu Z, Cheung R, Wu XY, Ballinger JR, Bendayan R, Rauth AM. A study of doxorubicin loading onto and release from sulfopropyl dextran ion-exchange microspheres. J Control Release 2001;77:213-24.

Cite this article as: Bhoyar PK, Amgaonkar YM. Taste masking and molecular properties of metformin hydrochloride-indion 234 complexes. J Young Pharmacists 2011;3:112-8.

Source of Support: Nil, Conflict of Interest: None declared.

Announcement

Android App

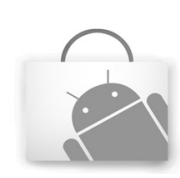
application

A free application to browse and search the journal's content is now available for Android based mobiles and devices. The application provides "Table of Contents" of the latest issues, which are stored on the device for future offline browsing. Internet connection is required to access the back issues and search facility. The application is compatible with all the versions of Android. The application can be downloaded from https://market.android.com/details?id=comm.app.medknow. For suggestions and comments do write back to us. 